\title{
The influence of type 2 diabetes mellitus on salivary matrix metalloproteinase- 8 levels and periodontal parameters: A study in an Indian population
}

\author{
Namita Gupta ${ }^{1}$, Narinder Dev Gupta $^{1}$, Akash Gupta $^{2}$, Lata Goyal ${ }^{1}$, Sagar Garg $^{3}$
}

Correspondence: Dr. Akash Gupta

Email:akash_inspace@yahoo.com

\author{
'Department of Periodontics and Community Dentistry, \\ Dr. Z. A. Dental College, Aligarh Muslim University, \\ Aligarh, Uttar Pradesh, India, \\ 2Department of Biochemistry, Subharti Medical \\ College, Meerut, Uttar Pradesh, India, \\ ${ }^{3}$ Department of Periodontics, Tamil Nadu Government \\ Medical College, Chennai, Tamil Nadu, India
}

\section{ABSTRACT}

Objective: Although many studies reported more severe periodontal disease and the existing proinflammatory conditions in patients with diabetes but only few have examined the effect of type 2 diabetes mellitus (DM) on salivary matrix metalloproteinase-8 (MMP-8) level and other periodontal parameters. This study aims to evaluate the effect of type 2 DM on salivary MMP-8 levels and periodontal parameters, which might be useful in monitoring periodontal disease in diabetes. Materials and Methods: A total of 90 subjects were selected for the study and were divided into three groups: Group I included 30 healthy subjects; Group II included 30 subjects without type 2 DM but with chronic periodontitis, and Group III included 30 subjects with type $2 \mathrm{DM}$ and chronic periodontitis. Periodontal parameters such as plaque index (PI), gingival index (GI), pocket probing depth (PPD), and clinical attachment level (CAL) were taken. The salivary MMP-8 level was estimated by Quantikine Human total MMP-8 immunoassay kit using ELISA method. Results: The mean value of the salivary MMP-8 of Group III was highest followed by Group II and Group I, the least. The other periodontal parameters PI, GI, PPD, CAL, was comparatively highest for Group III. Conclusion: This study suggests that diabetes is associated with an increased prevalence, extent, and severity of periodontitis. Furthermore, the increased levels of MMP-8 indicate the influence of diabetes on their salivary concentration.

Key words: Chronic periodontitis, matrix metalloproteinase-8, periodontal parameters, saliva, type 2 diabetes mellitus

\section{INTRODUCTION}

Mankind has been tormented by diseases of oral cavity since time immemorial. Periodontitis is a multifactorial inflammatory disease affecting the periodontal tissues, which is characterized by progressive destruction of the tissues supporting the tooth, and finally the outcome of untreated periodontitis is tooth loss. ${ }^{[1]}$ The role of host defense response is usually most important aspect in periodontitis mainly because it can determine both disease progression along with severity. ${ }^{[2]}$ Diabetes mellitus (DM) is one such wide existing endocrine disorder, which is known to alter this delicate balance thus imposing exaggerated tissue damage whenever challenged with a disease like periodontitis. ${ }^{[3,4]}$ Periodontal disease has been proposed as the sixth complication of diabetes. ${ }^{[5]}$ Diabetes itself does not trigger periodontitis nevertheless it predisposes and speeds up the irreversible periodontal destruction. Individuals with diabetes have increased defective polymorphonuclear function, increased collagenase

This is an open access article distributed under the terms of the Creative Commons Attribution-NonCommercial-ShareAlike 3.0 License, which allows others to remix, tweak, and build upon the work non-commercially, as long as the author is credited and the new creations are licensed under the identical terms.

For reprints contact: reprints@medknow.com

How to cite this article: Gupta N, Gupta ND, Gupta A, Goyal L,
Garg S. The influence of type 2 diabetes mellitus on salivary matrix
metalloproteinase-8 levels and periodontal parameters: A study in an
Indian population. Eur J Dent $2015 ; 9: 319-23$.
DOI: $10.4103 / 1305-7456.163222$


production, altered collagen and glycosaminoglycan synthesis, deregulation in cytokine production, and the formation of advanced glycation end products (AGEs); ${ }^{[6]}$ and they contribute to tissue destruction by inducing the release of cytokines through a multistep process, which ultimately leads to formation of more of matrix metalloproteinases (MMPs). ${ }^{[7]}$

Enzymes play a crucial role in the regulation of connective tissue destruction in periodontitis, most notably MMPs. Under normal physiological conditions, the expression of MMPs is considerably low, and these low levels are associated with healthy connective tissue remodeling. ${ }^{[8]}$ In pathologic conditions such as periodontitis, ${ }^{[9]}$ oral cysts, ${ }^{[10]}$ oral cancer, ${ }^{[11]}$ and atherosclerosis; $;^{[12]}$ the level of MMP expression enhances significantly, resulting in aberrant connective tissue destruction, hence leads to the elevation of MMP levels in saliva. MMPs are proteolytic enzymes belonging to zinc protease superfamily and are involved in physiological degradation of extracellular matrix protein and basement membrane. There are several groups of MMPs: Collagenase (MMP 1, 8, 13), gelatinase (MMP 2, 9), stromelysin (MMP 3, 10, 11), matrilysins (MMP 7), and other membrane associated MMPs $(2,3)$. In the present era, of periodontal medicine and therapeutics, traditional diagnostic aids such as probing depth and attachment loss have certain limitations. To overcome these challenges, researchers are trying to find out new biomarkers that can enable the clinicians in assessing and diagnosing the patient's condition better. ${ }^{[13]}$ Research shows MMP-8, a neutrophil collagenase, as a potential biomarker in chronic periodontitis, and it is highly correlated with bleeding on probing, probing pocket depth, and attachment loss. ${ }^{[1,15]}$ It has the unique ability to decompose Types I and III collagen. ${ }^{[16]}$ This study was aimed at understanding the contribution of type 2 $\mathrm{DM}$ in the pathogenesis of periodontitis. In order to achieve this goal, the periodontal parameters, and the levels of salivary MMP-8 were measured.

\section{MATERIALS AND METHODS}

\section{Patient selection}

The present study was conducted in the Department of Periodontology of Dr. Z. A Dental College, Aligarh Muslim University, Aligarh, India. This study was approved by the Institutional Review Board (Department of Periodontics and Community Dentistry, Aligarh Muslim University, Aligarh). All patients were individually informed about the study, and informed consent forms were signed in full accordance with the Helsinki Declaration.

\section{Groups}

A total of 90 (40 males and 41 females) individuals in the age range of $45-55$ years and having at least 20 teeths were taken into the study and were further divided into three groups: Group I: Healthy subjects, Group II: Chronic periodontitis patients without type 2 DM, and Group III: Chronic periodontitis with type 2 DM. Each group consisted of 30 subjects.

\section{Inclusion criteria \\ Group I}

Periodontally and systemically healthy individuals with no apparent signs of clinical inflammation.

\section{Group II}

Subjects with no systemic disease but clinically diagnosed with moderate to severe chronic periodontitis (e.g., at least two or more interproximal sites with clinical attachment level (CAL) of $\geq 4 \mathrm{~mm}$, or two or more interproximal sites with pocket probing depth (PPD) of $\geq 5 \mathrm{~mm}$, not on the same tooth). ${ }^{[17]}$

\section{Group III}

Subjects with type 2DM with current metabolic control above the normal range (glycated hemoglobin [HbA1c] test $>6 \%$ ) and clinically diagnosed with moderate to severe chronic periodontitis (e.g., at least two or more interproximal sites with CAL of $\geq 4 \mathrm{~mm}$, or two or more interproximal sites with PPD of $\geq 5 \mathrm{~mm}$, not on the same tooth).

\section{Exclusion criteria}

Exclusion criteria included smokers, pregnant and lactating women, and patients with acute or chronic medical disorders. Patients who had undergone any surgery in past 6 months, subjects undergoing orthodontic treatment were not included in the study.

\section{Clinical measurements}

Periodontal disease status of all patients was evaluated by measurement of plaque index (PI), ${ }^{[18]}$ gingival index (GI), ${ }^{[19]}$ PPD, and CAL. To rule out any bias, same instruments (University of North Carolina-15 probe [UNC-15], Hu-Freidy's USA) were used by the same examiner. Intraexaminer reliability of index reproducibility was assessed twice during the study in 10 patients by repeating the measurements (k-score for each measurement was never lower than 0.76). The pocket depth is the distance between the base of the pocket and the gingival margin. The distance was calculated with the UNC-15 probe held parallel to the vertical axis of the tooth. The pocket depth was measured at four sites per tooth. The CAL was calculated - It is the distance between the bases of the 
pocket to cemento-enamel junction. All patients were checked for their diabetic status by testing for $\mathrm{HbA1c}$ levels (by D-10 hemoglobin analyzer from Bio Rad). The same laboratory is used for testing for all the patients.

\section{Determination of matrix metalloproteinase-8 levels in saliva}

Saliva sample collection

The clinical parameters described above were recorded, and saliva samples necessary for estimation of MMP-8 were taken from all groups. Subjects were told not to eat or drink $2 \mathrm{~h}$ prior to the examination. They were seated comfortably, then asked to rinse and $3 \mathrm{ml}$ of unstimulated whole expectorated saliva was collected from each subject and placed into sterile $5 \mathrm{ml}$ saliva collecting tubes according to the method described by Navazesh. ${ }^{[20]}$ The collected saliva was centrifuged immediately to remove cell debris (1000 $\times g$ for $10 \mathrm{~min}$ at $4^{\circ} \mathrm{C}$ ). Then the supernatant was removed, and the sample was stored in small aliquots at $-80^{\circ} \mathrm{C}$ until analysis.

\section{MMP-8 levels Estimation}

Salivary MMP-8 levels were estimated for each subject using Quantikine Human total MMP-8 immunoassay kit using ELISA method, provided by R\&D Systems, (Minneapolis USA). Absorbance was read at $450 \mathrm{~nm}$, with the correction wavelength set at 540 or $570 \mathrm{~nm}$. The minimum detectable dose of MMP-8 ranged from 0.01 to $0.06 \mathrm{ng} / \mathrm{ml}$.

\section{Statistical analysis}

Continuous data were summarized as the mean \pm standard deviation while discrete (categorical) in percentage. Continuous variables were compared by one-way analysis of variance (ANOVA), and the significance of the mean difference between the groups was done by Tukey's post-hoc test. Categorical variables were compared by Chi-square test. The statistical significance of correlations among MMP-8 and periodontal parameters was determined using spearman rank correlation coefficients. A two-sided ( $\alpha$ $=2) P<0.05$ was considered as statistically significant. All analyses were performed on STATISTICA (Windows version 6.0 for 2001. StatSoft, Inc.,)

\section{RESULTS}

The mean values for the clinical parameters and demographic data of all the three groups are given in Table 1. No significant difference between the mean age was found among the three groups $(P>0.05)$. Similarly, no significant difference was found in the proportion of genders $(\mathrm{M} / \mathrm{F})$ between the three groups $(P>0.05)$.
Acomparison among all three groups showed a significant difference in periodontal parameters $(P<0.001)$. The mean PI, GI, PPD, CAL values of Groups II and III were significantly higher than those of Group I $(P<0.001)$, with the highest values in Group III.

MMP-8 levels: ANOVA revealed the mean values of salivary MMP-8 of Group II (381.60 \pm 57.66$)$ and III $(458.36 \pm 45.52)$ were significantly higher $(P<0.001)$ than Group I (205.04 \pm 89.14$)$, with the highest being in Group III. Further, Tukey test revealed that the mean MMP-8 levels of Groups I and III were significantly $(P<0.001)$ different as compared to Group I [Figure 1]. The data of Table 2 revealed a highly significant positive correlation $(r)$ between MMP-8 and periodontal parameters in the entire sample.

\section{DISCUSSION}

Current studies are in a support that in patients with diabetes, the incidence and severity of periodontitis are much greater as compared to nondiabetics, ${ }^{[21]}$ to the extent that periodontitis has been called the "sixth complication of diabetes." [5] The reason being a combination of various factors that render the host resistance weakened against periodontal pathogens. There is decreased PMN chemotaxis, an increase in the level of enzymes such as collagenase, elastase, and the decrease in collagen formation by fibroblasts that are responsible for the periodontal destruction. ${ }^{[22]}$

\begin{tabular}{|c|c|c|c|c|}
\hline Parameters & $\begin{array}{c}\text { Group I } \\
(n=30)\end{array}$ & $\begin{array}{c}\text { Group II } \\
(n=30)\end{array}$ & $\begin{array}{c}\text { Group III } \\
(n=30)\end{array}$ & $P$ \\
\hline Age (years) & $44.87 \pm 4.34$ & $46.80 \pm 4.92$ & $48.96 \pm 3.75$ & $0.427^{*}$ \\
\hline \multicolumn{5}{|l|}{ Gender (\%) } \\
\hline Male & 16 (53.3) & 16 (53.3) & $17(56.7)$ & $0.956^{*}$ \\
\hline Female & $14(46.7)$ & $14(46.7)$ & $13(43.3)$ & \\
\hline $\mathrm{PI}$ & $0.54 \pm 0.10$ & $1.57 \pm 0.39$ & $2.30 \pm 0.23$ & $<0.001^{* * *}$ \\
\hline GI & $0.52 \pm 0.10$ & $2.06 \pm 0.18$ & $2.45 \pm 0.17$ & $<0.001^{* * *}$ \\
\hline PPD & $2.10 \pm 0.24$ & $5.34 \pm 0.24$ & $6.06 \pm 0.37$ & $<0.001^{* * *}$ \\
\hline CAL & $0.60 \pm 0.07$ & $5.30 \pm 0.20$ & $5.97 \pm 0.42$ & $<0.001^{* * *}$ \\
\hline $\mathrm{HbA1c}$ & $4.78 \pm 0.42$ & $4.90 \pm 0.69$ & $7.03 \pm 0.65$ & - \\
\hline
\end{tabular}

Data are expressed as mean \pm SD. Group I (control): Periodontally and systemically healthy individuals with no apparent signs of clinical inflammation $(n=30)$, Group II (chronic periodontitis without type 2 DM): Subjects with no systemic disease but clinically diagnosed with moderate to severe chronic periodontitis (e.g., at least two or more interproximal sites with CAL of $\geq 4 \mathrm{~mm}$, or two or more interproximal sites with PPD of $\geq 5 \mathrm{~mm}$, not on the same tooth) $(n=30)$, Group III (chronic periodontitis with type 2 $\mathrm{DM}$ ): Subjects with type $2 \mathrm{DM}$ with current metabolic control above the normal range $(\mathrm{HbA} 1 \mathrm{c}$ test $>6 \%)$ and clinically diagnosed with moderate to severe chronic periodontitis (e.g., at least two or more interproximal sites with CAL of $\geq 4 \mathrm{~mm}$, or two or more interproximal sites with PPD of $\geq 5 \mathrm{~mm}$, not on the same tooth) $(n=30)$. *Not significant, ${ }^{* * *}$ Highly significant. PI: Plaque index, GI: Gingival index, PPD: Probing pocket depth, CAL: Clinical attachment level, $\mathrm{HbA1c}$ : Glycated hemoglobin, DM: Diabetes mellitus 


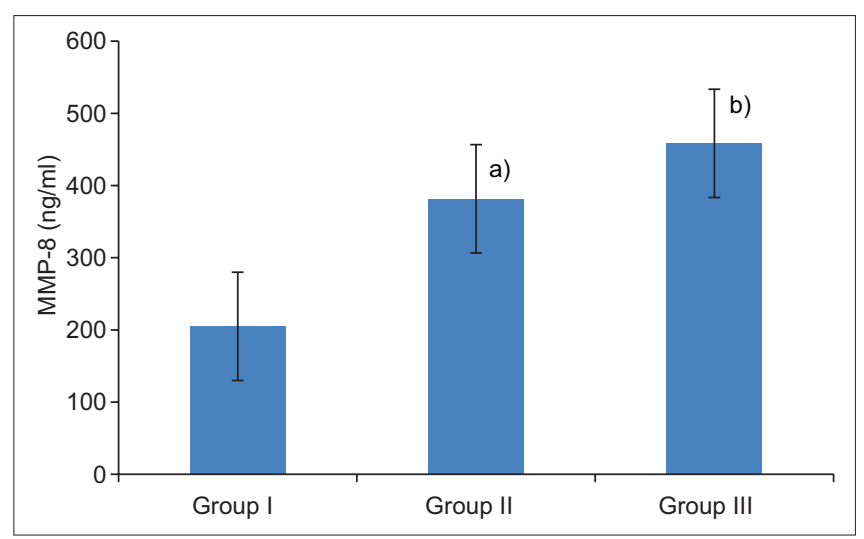

Figure 1: Salivary MMP-8 levels (mean \pm SD) of three groups. Group I (control), Group II (chronic periodontitis without type 2 DM, Group III (chronic periodontitis with type $2 \mathrm{DM}$ ). In Group III, the levels of MMP-8 were significantly increased as compared to group II and group I. a) Statistically significant difference as compared between group I and II $(P<0.001)$. b) Statistically significant difference as compared between groups II and III $(P<0.001)$

\begin{tabular}{|c|c|c|}
\hline Parameters & Correlation $(r)$ value & $P^{*}$ \\
\hline $\mathrm{PI}$ & 0.74 & 0.000 \\
\hline GI & 0.72 & 0.000 \\
\hline PPD & 0.80 & 0.000 \\
\hline CAL & 0.78 & 0.000 \\
\hline
\end{tabular}

${ }^{*}$ Correlation is significant at the 0.01 level (two-tailed). PI: Plaque index GI: Gingival index, PPD: Probing pocket depth, CAL: Clinical attachment level, MMP-8: Matrix metalloproteinase-8

Our results corroborate the findings of several studies reporting a positive association between diabetes and periodontal disease, which reported a greater risk of attachment loss and bone loss in diabetic patients. ${ }^{[23,24]}$ In diabetes, the formation of collagen and glycosaminoglycan is impaired, collagenolytic activity of gingival crevice fluid is increased, which in turn causes loss of periodontal fibers, loss of the alveolar bone, and finally results in exfoliation of the teeth. ${ }^{[25]}$ Moreover, in the present study, it was found that the value of GI was higher for diabetics as compared to nondiabetic patients, which concur with the finding reported by Cutler et al. ${ }^{[26]}$ and Ervasti et al..$^{[27]}$ who reported that poorly controlled diabetics had mean GI score of $77.9 \pm 19.2$ as compared to $61.9 \pm 25.1$ in the control group, and it was statistically significant. This may be due to the metabolic imbalances in the tissue which can lower the resistance to infection in diabetic individuals. Decrease in response to inflammation may also be due to impaired neutrophil chemotaxis in diabetic patients. ${ }^{[28]}$

MMP-8 has been considered as a key biomarker in chronic periodontitis. ${ }^{[29]}$ It is a major collagenolytic metalloproteinasein gingival tissues and oralfluids, and its elevated level is associated with the severity of periodontal inflammation. ${ }^{[14]}$ In this study, the quantitative analysis of MMP-8 showed that MMP-8 levels was significantly increased in patients with type 2 diabetic (Group III) as compared to nondiabetics (Group II), although both having generalized chronic periodontitis. Thus, the difference between MMP-8 levels in Groups II and III was because of periodontal destruction, which is more in type 2 diabetes. A possible justification pertaining to this could be that in diabetes, collagen crosslinking occurs due to the formation of AGE that could induce a cycle of cytokine up-regulation after binding to macrophage receptors. This results in an elevated expression of MMP in diabetic periodontal tissues. ${ }^{[30]}$ Comparing the rise of MMP-8 levels, which shows a higher mean salivary MMP-8 in diabetic patients as compared to nondiabetic and control group is highly in conformity with the result obtained by Costa et al. ${ }^{[31]}$ who observed highest concentrations of MMP-8 in the saliva of patients with diabetes. Our result also comes in agreement with the results of Collin et al., ${ }^{[32]}$ Kumar et al., ${ }^{[33]}$ which found a rise in MMP-8 levels as compared to nondiabetics controls in saliva. Another study by Rathnayake et al. ${ }^{[34]}$ also revealed that patients with diabetes had a 3 times higher ratio of the MMP-8/TIMP-1 and twice as high concentration of MMP-8. Furthermore, in the present study, the MMP-8 concentration had a significant positive correlation with periodontal indices. This indicates that periodontal disease severity was increased with the values of MMP-8, and it has a strong association between periodontal parameters and MMP-8.

Unstimulated saliva was used as the sample for study. Using saliva for sampling has certain advantages such as the easy collection, noninvasive, and rapid procedure; moreover, it can be collected from all the sites in the mouth giving an overall assessment of disease status and severity ${ }^{\left[{ }^{[5]}\right.}$ Furthermore, its measurement does not require any special equipment and expertise.

Diabetes is certainly one of the biggest and most serious risk factor in development and progression of periodontitis as the latter is significantly aggravated in patients suffering from diabetes having long-term hyperglycemia. ${ }^{[36]}$ Although a lot has been achieved in establishing the association between the accelerated periodontal disease and diabetes, butmore breakthroughs are needed. While the finding of the study could be applied in most instances, there were some limitations of this study, such as the sample size was small. Thus, studies with larger sample size should be done so that various associated risk factors could be studied in detail. 
Gupta, et al.: Impact of type 2 diabetes mellitus on periodontal status and matrix metalloproteinase-8

\section{CONCLUSION}

In summary, the current study suggests that the diabetes is a major risk factor that exerts a negative effect on periodontal tissues, which contribute to an enhanced susceptibility to periodontitis. Furthermore, the increased levels of MMP-8 in saliva clearly point toward active periodontitis in diabetic patients. This opens up new possibilities in future, specific immunoassays targeting MMPs, especially MMP-8 or collagenase- 2 from oral fluids, could prove out to be useful in monitoring the course of periodontitis in patients with diabetes.

\section{Acknowledgments}

The authors are grateful to all the participants in this study and to the Department of Periodontics and Community Dentistry, Dr. Z. A. Dental College, Aligarh Muslim University, Aligarh, India. All the authors have significantly contributed in the study.

\section{Financial support and sponsorship}

Nil.

\section{Conflicts of interest}

There are no conflicts of interest.

\section{REFERENCES}

1. Nunn ME. Understanding the etiology of periodontitis: An overview of periodontal risk factors. Periodontol 2000 2003;32:11-23.

2. Seymour GJ, Gemmell E, Reinhardt RA, Eastcott J, Taubman MA. Immunopathogenesis of chronic inflammatory periodontal disease: Cellular and molecular mechanisms. J Periodontal Res 1993;28:478-86.

3. Shlossman M, Knowler WC, Pettitt DJ, Genco RJ. Type 2 diabetes mellitus and periodontal disease. J Am Dent Assoc 1990;121:532-6.

4. Mealey BL, Ocampo GL. Diabetes mellitus and periodontal disease. Periodontol 2000 2007:44:127-53.

5. Löe H. Periodontal disease. The sixth complication of diabetes mellitus. Diabetes Care 1993;16:329-34

6. Schmidt AM, Hori O, Cao R, Yan SD, Brett J, Wautier JL, et al. RAGE: A novel cellular receptor for advanced glycation end products. Diabetes 1996;45:S77-80.

7. Ryan ME, Ramamurthy NS, Sorsa T, Golub LM. MMP-mediated events in diabetes. Ann N Y Acad Sci 1999:878:311-34.

8. Nagase H, Woessner JF Jr. Matrix metalloproteinases. J Biol Chem 1999;274:21491-4.

9. Bertoldi C, Lalla M, Pradelli JM, Cortellini P, Lucchi A, Zaffe D. Risk factors and socioeconomic condition effects on periodontal and dental health: A pilot study among adults over 50 years of age. Eur J Dent 2013;7:336-46.

10. Wahlgren J, Maisi P, Sorsa T, Sutinen M, Tervahartiala T, Pirilä E, et al. Expression and induction of collagenases (MMP-8 and -13) in plasma cells associated with bone-destructive lesions. J Pathol 2001;194:217-24.

11. Moilanen M, Pirilä E, Grénman R, Sorsa T, Salo T. Expression and regulation of collagenase-2 (MMP-8) in head and neck squamous cell carcinomas. J Pathol 2002;197:72-81.

12. Krupinski J, Turu MM, Font MA, Ahmed N, Sullivan M, Rubio F, et al. Increased tissue factor, MMP-8, and D-dimer expression in diabetic patients with unstable advanced carotid atherosclerosis. Vasc Health Risk Manag 2007;3:405-12.

13. Fine DH, Mandel ID. Indicators of periodontal disease activity: An evaluation. J Clin Periodontol 1986;13:533-46.

14. Giannobile WV, Beikler T, Kinney JS, Ramseier CA, Morelli T, Wong DT. Saliva as a diagnostic tool for periodontal disease: Current state and future directions. Periodontol 2000 2009;50:52-64.
15. Kraft-Neumärker M, Lorenz $K$, Koch R, Hoffmann T, Mäntylä $P$, Sorsa T, et al. Full-mouth profile of active MMP-8 in periodontitis patients. J Periodontal Res 2012;47:121-8.

16. Sorsa T, Tjäderhane L, Konttinen YT, Lauhio A, Salo T, Lee HM, et al. Matrix metalloproteinases: Contribution to pathogenesis, diagnosis and treatment of periodontal inflammation. Ann Med 2006;38:306-21.

17. Page RC, Eke PI. Case definitions for use in population-based surveillance of periodontitis. J Periodontol 2007;78:1387-99.

18. Silness J, Loe H. Periodontal disease in pregnancy. II. Correlation between oral hygiene and periodontal condtion. Acta Odontol Scand 1964;22:121-35.

19. Loe H, Silness J. Periodontal disease in pregnancy. I. Prevalence and severity. Acta Odontol Scand 1963;21:533-51.

20. Navazesh M. Methods for collecting saliva. Ann N Y Acad Sci 1993;694:72-7.

21. Cifcibasi E, Kantarci A, Badur S, Issever H, Cintan S. Impact of metronidazole and amoxicillin combination on matrix metalloproteinases- 1 and tissue inhibitors of matrix metalloproteinases balance in generalized aggressive periodontitis. Eur J Dent 2015;9:53-9.

22. Mealey BL, Oates TW, American academy of periodontology. Diabetes mellitus and periodontal diseases. J Periodontol 2006;77:1289-303.

23. Campus G, Salem A, Uzzau S, Baldoni E, Tonolo G. Diabetes and periodontal disease: A case-control study. J Periodontol 2005;76:418-25

24. Collin HL, Uusitupa M, Niskanen L, Kontturi-Närhi V, Markkanen H, Koivisto AM, et al. Periodontal findings in elderly patients with non-insulin dependent diabetes mellitus. J Periodontol 1998;69:962-6

25. Kiran M, Arpak N, Unsal E, Erdogan MF. The effect of improved periodontal health on metabolic control in type 2 diabetes mellitus. J Clin Periodontol 2005;32:266-72.

26. Cutler CW, Machen RL, Jotwani R, Iacopino AM. Heightened gingival inflammation and attachment loss in type 2 diabetics with hyperlipidemia. J Periodontol 1999;70:1313-21.

27. Ervasti T, Knuuttila M, Pohjamo L, Haukipuro K. Relation between control of diabetes and gingival bleeding. J Periodontol 1985;56:154-7.

28. Alba-Loureiro TC, Munhoz CD, Martins JO, Cerchiaro GA, Scavone C, Curi R, et al. Neutrophil function and metabolism in individuals with diabetes mellitus. Braz J Med Biol Res 2007;40:1037-44.

29. Gursoy UK, Könönen E, Huumonen S, Tervahartiala T, Pussinen PJ, Suominen AL, et al. Salivary type I collagen degradation end-products and related matrix metalloproteinases in periodontitis. J Clin Periodontol 2013;40:18-25

30. Lalla E, Lamster IB, Stern DM, Schmidt AM. Receptor for advanced glycation end products, inflammation, and accelerated periodontal disease in diabetes: Mechanisms and insights into therapeutic modalities. Ann Periodontol 2001;6:113-8.

31. Costa PP, Trevisan GL, Macedo GO, Palioto DB, Souza SL, Grisi MF, et al. Salivary interleukin-6, matrix metalloproteinase-8, and osteoprotegerin in patients with periodontitis and diabetes. J Periodontol 2010;81:384-91.

32. Collin HL, Sorsa T, Meurman JH, Niskanen L, Salo T, Rönkä H, et al. Salivary matrix metalloproteinase (MMP-8) levels and gelatinase (MMP-9) activities in patients with type 2 diabetes mellitus. J Periodontal Res 2000;35:259-65.

33. Kumar MS, Vamsi G, Sripriya R, Sehgal PK. Expression of matrix metalloproteinases (MMP-8 and -9) in chronic periodontitis patients with and without diabetes mellitus. J Periodontol 2006;77:1803-8.

34. Rathnayake N, Akerman S, Klinge B, Lundegren N, Jansson H, Tryselius Y, et al. Salivary biomarkers for detection of systemic diseases. PLoS One 2013;8:e61356.

35. Miller CS, King CP Jr, Langub MC, Kryscio RJ, Thomas MV. Salivary biomarkers of existing periodontal disease: A cross-sectional study. J Am Dent Assoc 2006;137:322-9.

36. Deshpande K, Jain A, Sharma R, Prashar S, Jain R. Diabetes and periodontitis. J Indian Soc Periodontol 2010;14:207-12.

\begin{tabular}{|l|l|}
\hline \multicolumn{2}{|c|}{ Access this article online } \\
\hline Quick Response Code: & \\
\hline
\end{tabular}

